\title{
Analysis of Inlet and Outlet System of Racing Engine and Influence of Various Configurations on Brake Mean Effective Pressure
}

\author{
Michal Puškár *, Melichar Kopas \\ Technical University of Košice, Faculty of Mechanical Engineering, Department of Engineering for Machine Design, Automotive and Transport, Letná 9, \\ 04002 Košice Slovakia
}

doc. Ing. Michal Puškár, PhD. Is a researcher at the Department of Engineering for Machine Design, Automotive and Transport at the Faculty of Mechanical Engineering, Technical University of Košice. He graduated at the mentioned Department in 2005 and the PhD.degree received in 2008 with theme of his dissertation thesis: Rising of Power Parameters of Single-Track Transport Means. His current fields of research interest are single-track transport means, piston combustion engines and increasing of their power output and reliability.

Ing. Melichar Kopas, PhD. Is an assistant lecturer at the Department of Engineering for Machine Design, Automotive and Transport at the Faculty of Mechanical Engineering, Technical University of Košice. He graduated at the Department of Transport and Handling Machines, which was a predecessor of the above-mentioned Department in 1988. The PhD.-degree he obtained with the dissertation thesis target on the theoretical and practical questions concerning the transport systems of bulk materials. His research activities are focused on the driving mechanisms and transmissions designed for the transport and handling machines or machineries as well as on the theory and construction of the mechanical conveyors for bulk solids.

\begin{abstract}
This article is focused on experimental analysis of acoustic wave influences on the brake mean effective pressure. An experimental base was created using a racing motorbike driven by piston combustion engine, which is equipped with a developed inlet pipe. The inlet air pressure value changed from the atmospheric level to the under-pressure level. This change is connected directly with increasing of the power output and torque. The tuned racing outlet system was applied for measuring of the outlet pipe characteristics. There were investigated influences of the individual configurations in the case of both analysed systems by means of the sequential experimental measurements. During measurement performed using the final configuration of the inlet system there was recorded an increment of the power output on high speed what is illustrated at comparison of global benefit relating to the basic version. The presented inlet pipe was successful in the motorsport area and it was patented, as well.
\end{abstract}

Keywords: Combustion engine, inlet system, outlet system. 


\section{Introduction}

An analysis of the engine performance as well as criteria for developing of the inlet and exhaust pipe system require the deep knowledge about acoustics of the both systems. The up-todate known information from this area can be summarized into several conclusions.

In many scientific articles there are presented experimental results and theoretical models of the acoustic waves and their impact on global efficiency of the piston combustion engines. The fundamental information sources about the instable gas dynamics in internal distribution channels of combustion engines were presented during the 50's of the last century. Measuring methods of the local throughput in the pipe, together with computerised calculations, were improved considerably during the 80's, [1]. A complete overview of topical knowledge oriented to the analysis and proposal of the inlet (suction) and exhaust systems of the internal combustion engine was published at the end of the 90's, [2]. The theoretical principia of one-dimensional acoustic models were described at the turn of the centuries. At that time the more complicated non-linear dynamic gas models were transformed successfully to the simpler linear acoustic models, [3].

Very interesting results were obtained also by means of the Euler's equation solution for a pipe. This solution offered a high level of result reliability, [4]. A principle of this methodology consists in solution of velocities and pressure equations with regard to the frequency using a method of matrix transfer, taking into consideration also theoretical limits for real values of the high-pressure levels in the exhaust gas system. This solution seems to be the most suitable method for analysis of the inlet and exhaust system with regard to noise reduction, [5].

Some of the scientific works are demonstrating a acceptable conformity of the linear acoustic models with the experiments performed in the inlet and exhaust pipe of the piston combustion engines, [6]. A wide range of the experimental tests and practical applications are supporting the development criteria for proposal of new theories. They are integrating together a lot of results obtained from the research activities performed in the area of resonance and acoustic feedback among the inlet parts. At the same time the above-mentioned amount of information enables to propose the new methods for projection of the inlet and exhaust systems of the piston engines, [7].

A complex view on design and simulation of the high-power engines, including a proposal of the empirical methods for designers as well as the experimental data about efficiency of the highspeed engines, are summarized in the literature [8]

In spite of a large amount of the publications and professional articles there is at disposal only a small amount of the measured data concerning mutual interrelations and influences among the individual parts of the inlet system. An arrangement of the inlet system is independent usually on a constructional and technological conception of the engine itself in the case of the high-power combustion engines. This article presents an experimental study of the high-power combustion engine applied in the motorbike, which was specified for the racing purposes. In this article there is investigated an influence of the various inlet and exhaust systems as well as their individual components on the volumetric efficiency. This investigation was performed by means of the various measurements using the data-recording system.

The several various inlet and exhaust system configurations were tested during this research process. The final complete configuration of the inlet system, which is presented in the Fig.1, is a result of our own long-time development process. Another output of the successful development activities is also the patent application of this invention, which was registered in the last year. This patent concerns a conceptual arrangement of the newly developed system.

This experimental analysis was realised according to various remarks and problem solutions occurring during realisation of various engine design, [9].

\section{Tested Engine}

The high-power racing motorbike engine was chosen for the practical tests in order to perform the individual experimental measurements. This engine is based on a serial engine production. The simplified scheme of the given engine is presented in the Fig.1, together with the inlet and exhaust system. All other relevant technical data about this engine are summarized in the Table 1. 
Table 1: Technical Parameters of the Test Engine.

\begin{tabular}{|l|l|}
\hline Type & $\begin{array}{l}\text { Single-cylinder, two-stroke } \\
\text { engine, liquid cooled, membrane } \\
\text { filled, an electrical-controlled }\end{array}$ \\
\hline Capacity & $124.8 \mathrm{~cm}^{3}$ \\
\hline Bore x Stroke & $54 \times 54.5 \mathrm{~mm}$ \\
\hline Type of the exhaust and inlet system & Resonance inlet and exhaust system \\
\hline
\end{tabular}

\section{Inlet and Exhaust Systems}

The motorcar engines are using usually such system of supercharging, which is based on the turbine driven by the exhaust gases, i.e. the socalled turbocharging or turbo. This system can be applied also in the case of motorbike engines; however various problems come into existence and the final supercharging effect is insufficient. A possible solution of this task offers a system of the thrust loading suction, which is applied for the high-power motorbike engines because of its simplicity. A disadvantage of such solution is a fact that the sufficient level of overpressure, which is necessary for production of an efficient engine power output, is generated only at high speed levels of the vehicle (over $120 \mathrm{~km} \cdot \mathrm{h}^{-1}$ at least and over $150 \mathrm{~km} \cdot \mathrm{h}^{-1}$ in an ideal case). If the speed value is under these limits, the effect is almost none and vice-versa in such situation there is able to be occurred an undesirable under-pressure in the intake system.

It is necessary from this reason to develop such new system, which will be able to generate the required effect of the pressurized air inlet also during lower speeds as well as without a motion of the vehicle.

The newly developed inlet system installed in the engine, together with the resonance exhaust system as well as the motorbike silhouette are visible in the Fig. 1. The blue arrows are marking flowing of the fresh incoming air; the red arrows are illustrating streaming of the exhaust gases in the resonance exhaust system. This inlet system is a subject of the registered patent application with the title "System of the thrust-ejector suction". This invention consists in the following design proposal: the suction inlet (1) is installed at the frontal surface of the vehicle. The suction inlet is connected with the inlet pipe (2), which is jointed with the ejector (3). The ejector is fixed to the compression pipeline (4). The compression pipeline is connected air- tightly with the air accumulator (airbox) (5) and with the diffuser of carburettor is coming to the airbox.

A supposed advantage of this construction should be a possibility of partial supercharging also in a static state of the vehicle. This assumption is based on the results obtained during testing of the engine prototype equipped with this new system. It was necessary to increase an amount of the delivered fuel during stationary measurements on the engine power brake because the new system reduced the fuel mixture as a result of the pressurized air inlet. The increasing values of the engine torque were recorded by means of the datarecording during the performed experiments (Fig. 14).

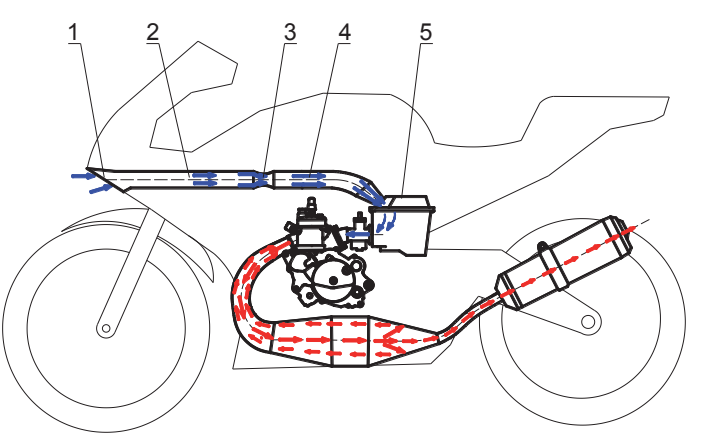

Fig. 1: The developed inlet system with the engine and with the resonance exhaust system.

The Fig. 2 offers a more complex description of the individual parts of the inlet and exhaust system. The complete inlet system with the external and internal air part is divided into the three main subsystems: the secondary pipeline, the airbox and the primary pipeline. The secondary pipeline is feeding outer air from the frontal surface of the motorbike to the airbox. The airbox is an airtight box, which connects the secondary pipeline with the primary pipeline including carburettor and the set of membrane suction valve. The geometrical characteristics of the inlet and exhaust channels in the engine cylinder were modified in order to improve the aerodynamic power output.

The exhaust pipe is a classic resonance exhaust system with the components described in the Fig. 2 in details.

The Tab. 2 presents the main dimensions of 
the inlet and exhaust system of this engine. The silencer is an absorptive type and it is made from the external steel shell with the thickness $1 \mathrm{~mm}$. It is filled by an absorptive inlet, which is covering the steel tube with the perforated middle part.

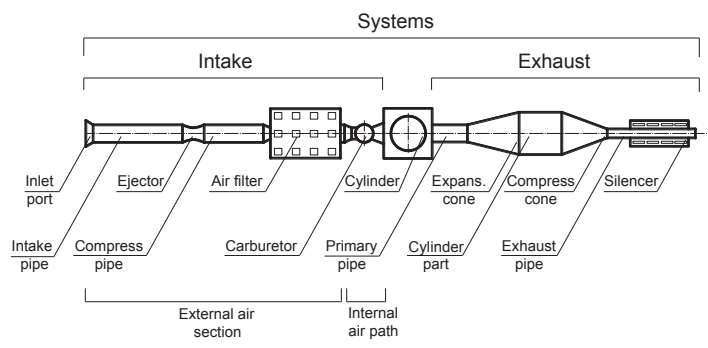

Fig. 2: Components of the intake and exhaust system.

\section{Measuring Equipment}

The engine was tested in a real loading by means of the system EW\&C. It is a data-recording system, i.e. it is equipment, which is sensing information during the engine current operation under real conditions and it is saving (recording) simultaneously the necessary information into the internal memory. The data-recording system enables monitoring of the all important combustion engine parameters, namely the engine power output and the engine torque in dependence on the engine speed. Also the exhaust system temperature and its time behaviour is measured as well as many other parameters. The concrete number and kind of the recorded parameters depends on a type and amount of the sensors installed in the given engine. The Fig. 3 illustrates a fundamental scheme of the equipment, which is used for the data measuring, elaboration and evaluation.

It is evident from this figure that the principle of this system operation consists in the monitoring of an actual engine speed, a temperature of the exhaust system and the speed gear. An additional input parameter can be also the throttle position in the carburettor. The measuring system is able to create a record of the current engine operation by means of the above-mentioned measured data taking into consideration also the next supplemental information (e.g. the wheel circuit, gear ratios of the individual speed gears, a curve of the air resistance and a mass of the motorcycle). This operational record is being saved into the system

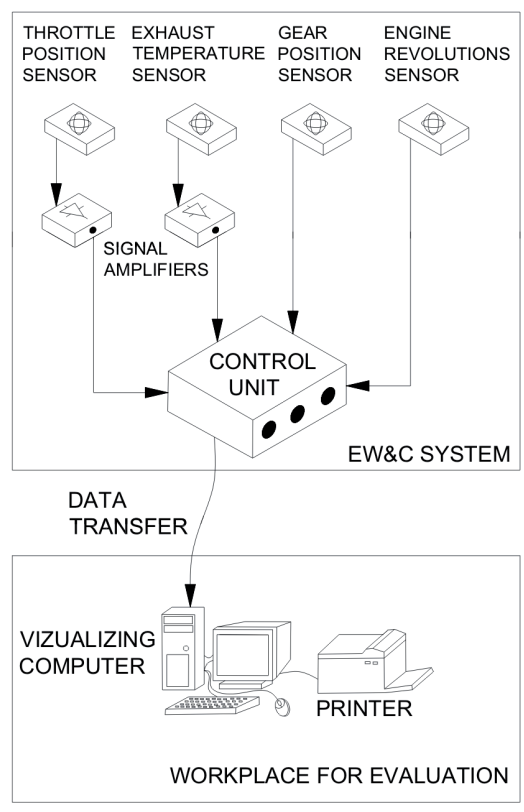

Fig. 3: Scheme of the EW\&C system.

internal memory continuously and after finishing of the measuring it is copied into the PC. The time behaviour of the engine operation is displayed on the monitor. Each point of the obtained record represents a multi-functional source of information about the momentary speed, exhaust system temperature as well as about the engine power output, which is measured on the crankshaft.

In the framework of the whole speed spectrum range there was necessary to accomplish several tests in order to perform the power output analysis of the various inlet and exhaust system configurations. Every measuring had to be repeated three-times at least for a verification of the accuracy and for reliability. All tests are running at the 4th speed gear what ensures an operational stability in the whole speed spectrum taking into consideration the special racing requirements. The experimental measurements presented in this paper are described in the form of the output diagrams created according to a similarity of two basic parameters: the break mean effective pressure bmep and the piston speed um. The diagrams are assembled using the factor values bmepmax $=1.77 \mathrm{MPa}$ and $u \operatorname{mmax}=21.6 \mathrm{~m} \cdot \mathrm{s}^{-1}$, i.e. by means of the maximum values of the break mean effective pressure and the piston speed. These data were obtained from the engine testing at the 4th speed 
gear and after the specific racing adjustment. A sketch of the appropriate testing configurations of the both systems is also a component part of the characteristics. All the relevant relations between the engine power output and the engine speed as well as between the engine torque and the engine speed can be obtained from the above-mentioned curves.

\section{Acoustics in the Inlet Pipeline}

There were tested several various design configurations in order to analyse an influence of the inlet and exhaust system components. These systems were disassembled into the individual parts firstly and after then the individual components were mounted together into the partial systems and in this way the final configuration was designed, which is illustrated in the Fig. 2.

The scheme of the inlet and exhaust pipe is in the Fig. 4. The secondary inlet pipe is presented in the upper part of this figure and the exhaust system is in the bottom part. Both pipelines are divided into the subsystems, which are marked Ai,e - Fi,e. The main dimensions of all pipe subsystems are given in the Tab. 2. According to these dimensions was created a graphical dependence between the pipe diameter and its distance from the cylinder. This relation is visible in the Fig. 5 .

Table 2: Main dimensions of inlet and exhaust system.
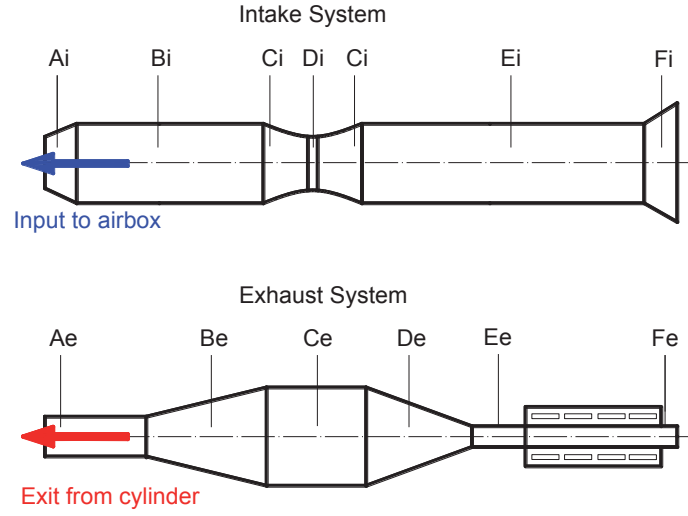

Fig. 4: Scheme of the inlet and exhaust pipe.

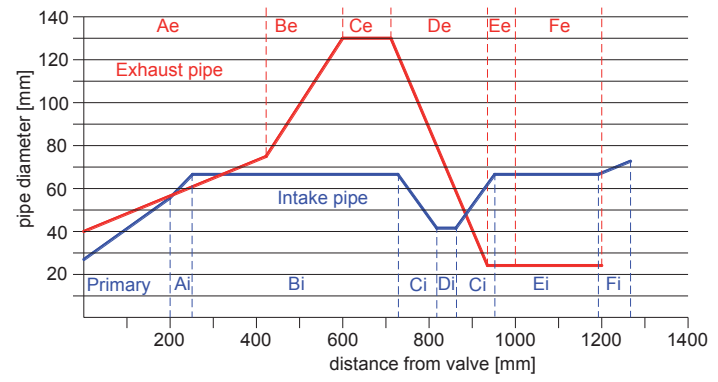

Fig. 5: Main dimensions of the inlet and exhaust pipe.

The complete configuration of the inlet and exhaust system is in the Fig. 2. This configuration was chosen in order to obtain more information

\begin{tabular}{|c|c|c|c|c|c|c|}
\hline System & & Subsystem & Mark (Fig.4,5) & Length [mm] & Input diameter [mm] & Output diameter [mm] \\
\hline \multirow{8}{*}{ Inlet } & \multirow{7}{*}{ External air section } & Inlet port & $\mathrm{Fi}$ & 40 & 70 & 65 \\
\hline & & Inlet pipe & $\mathrm{Ei}$ & 270 & 65 & 65 \\
\hline & & \multirow{2}{*}{ Ejector } & $\mathrm{Ci}$ & 75 & 65 & 40 \\
\hline & & & $\mathrm{Di}$ & 25 & 40 & 40 \\
\hline & & Compress pipe & $\mathrm{Bi}$ & 475 & 65 & 65 \\
\hline & & Connecting pipe & $\mathrm{Ai}$ & 75 & 65 & 55 \\
\hline & & Air filter & & \multicolumn{3}{|c|}{ Length xWidth x High $(185$ x 110 × 200) [mm] } \\
\hline & Internal air path & Primary pipe (Include carburettor) & Primary & 200 & 28 & 55 \\
\hline \multirow{7}{*}{ Exhaust } & Primary nino & Standard & \multirow{2}{*}{$\mathrm{Ae}$} & 430 & \multirow{2}{*}{40} & \multirow{2}{*}{75} \\
\hline & Pmindary pipe & Trim & & 420 & & \\
\hline & Expansion cone & Be & 178 & 75 & 130 & \\
\hline & Cylinder part & Ce & 98 & 130 & 130 & \\
\hline & Compression cone & De & 210 & 130 & 24 & \\
\hline & Exhaust pipe & Ee & 82 & 24 & 24 & \\
\hline & Silencer & $\mathrm{Fe}$ & 200 & 24 & 24 & \\
\hline
\end{tabular}


about the engine power output of the inlet and exhaust pipe. The output information obtained from this configuration, including values of an optimal temperature interval (Fig.6), was compared with the outputs from other subsystem configurations or with other temperature intervals,

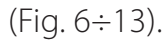

If there is taken into consideration a linear relation between the bmep and the torque, so the peaks of the bmep correspond to the maximums of the torque and efficiency. There is neglected in this case a reduction of the engine speed due to the mechanical loses. It is possible in this way to estimate the peaks of the curves by means of the simplified equations that are derived from the theoretical wave models, [2]. The ideal natural frequencies typical for the inlet system of combustion engines are calculated in the literature [10]. The inlet of air from the primary pipe is jointed with the secondary pipe by means of the connecting chamber (airbox). During the suction time is generated a wave effect, which creates a maximal volumetric efficiency of the air inlet. The maximal wave frequencies can be approximated according to the following equations (1) and (2):

$\cos \left(\frac{\omega \times l_{p}}{c_{s}}\right)=0$

$$
\begin{aligned}
& A_{\mathrm{sec}} \times A_{p r} \times \cot \left(\frac{\omega \times l_{\mathrm{sec}}}{c_{s}}\right)=\frac{\omega \times V_{p l}}{c_{s} \times A_{p r}}+ \\
& +4 \times \tan \left(\frac{\omega \times l_{p}}{c_{s}}\right)
\end{aligned}
$$

where: $\omega$ is the natural frequency of the system, $l_{p}$ and $l_{\text {sec }}$ are the primary and secondary lengths of pipes in the section $A_{p r}$ and $A_{s e c}, V_{p l}$ is the volume of connecting chamber between the primary and the secondary tube, $c$ is the speed of sound,

The equation (2) does not offer any useful information in this case because the frequency value $\omega$ for the whole system is deep under the minimal operational speed of this engine. Instead of this, the air streaming is illustrated in the Fig. 1 by means of the primary pipe length. The equation (1) enables to define the maximum point of the volumetric efficiency.
The wave effect is able to increase the volumetric efficiency because it is generating the resonance phenomena as a result of the pressure impulses arising during closing of the membrane valve. The newest publication [11] defines also the next equation (3) of speed $N_{i}$ for variable parts of the inlet pipe, where $n_{i}$ is a number of pressure impulses entering the pipe during $720^{\circ}$ rotation of the crank-shaft:

$$
\frac{N_{i}}{2}=\frac{1}{2 \times n_{i}} \times \frac{c_{s}}{2 \times l_{p}} \times\left(\sum_{j} \frac{K_{j}}{1-\left(1.62 \times \frac{u m\left(N_{i}\right)}{c_{s}} \times \frac{A_{p}}{A_{j}}\right)^{2}}\right)^{-1}
$$

where: $l_{p}$ is the total pipe length, which is divided into the $j$ pipe subsystems with the constant section $A_{i}$ and length each of them is $K_{j} l_{p}, A_{p}$ is the piston area, $u m\left(N_{i}\right)$ is the piston speed.

The number and position of the impulse peaks can be defined by means of the equation (2). It is possible to say, according to our own experiences, that this simplified relation requires also an additional tuning. However, it should be sufficient for a practical proposal of the racing engine pipes.

\section{Acoustics in the Exhaust Pipe}

The silencer influence on the torque during the optimal operational temperature using the complete set of the inlet and exhaust system is demonstrated in the Fig. 9. It is not evident a relevant difference among the braking torque values without and with the silencer. Some deviations are visible but they are in limits and they can be regarded as a measuring error. This system arrangement is useful only for obtaining of information and it is not applicable for the practical purposes due to the noise restrictions. The equation (3) is valid for the inlet pipe. The simplified analytical equation (4) is appropriate for tuning of the exhaust pipe:

$$
\frac{2 \times \pi \times N}{\theta_{e}}=\frac{c_{s}}{l_{e}} \times\left(\frac{3-\frac{u m(N)}{c_{s}} \times \frac{A_{p}}{A_{e}} \times \frac{T_{e}}{T_{a i r}}}{1-\left(\frac{u m(N)}{c_{s}} \times \frac{A_{p}}{A_{e}} \times \frac{T_{e}}{T_{\text {air }}}\right)^{2}}\right)^{-1}
$$


The tuning regime $\mathrm{N}$ with the $83 \%$ value of the $u_{\text {max }}$ (peak on the right in the Fig. 6) is an assumption for the equation (4), whereas the average value of the exhaust gas temperature $T_{e}$ is from the interval $520^{\circ} \div 620^{\circ} \mathrm{C}$ and the length of the exhaust gas is $l_{e}$. The initial analysis of the exhaust system was oriented to determination of an optimal temperature interval in the exhaust system.

The speed of sound waves is increasing if the temperature is higher. This fact is in accordance with the theory of waving taking into consideration the relation (5) between the speed of sound waves and the air temperature:

$$
C=\sqrt{K \times \frac{R \times T}{M}}
$$

where: $C$ is the speed of sound waves, $K=1.4, R$ is the universal gas constant, $T$ is the temperature, $M$ is the molar mass.

If the exhaust pipe is defined with regard to its shape and dimensions, so in this case there exists theoretically such temperature interval, which is limited by the maximum and minimum temperature values. The output engine characteristics are optimal in this interval. With regard to this assumption, there were performed the measurements focused on determination of the temperature interval, which is optimal for the given exhaust system. The thermal sensor was installed in the point of maximal temperature in the exhaust system, i.e. in the area of the primary pipe [12], approx. $150 \mathrm{~mm}$ from the upper edge of the exhaust channel (Fig. 2).

The increasing temperature of the exhaust system accelerates the resonance wave propagations. The back-wave in the exhaust pipe is returning faster. In this way the process of the cylinder reverse scavenging is also accelerated and the exhaust pipe is shortening theoretically. If the engine speed is increasing during the optimal regime, so the exhaust system temperature must be higher. Thus, the exhaust system is shorter theoretically at higher speed and longer theoretically (with a lower temperature) in slower engine speed $[13,14]$.

The Fig.6 illustrates graphically a comparison of the output parameters of the complete inlet and exhaust pipes for two various temperature intervals. The vertical axis represents a ratio between the break mean effective pressure bmep and the maximum of the break mean effective

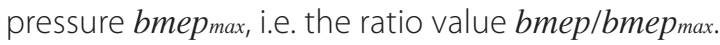
The horizontal axis represents a ratio between the piston speed $u m$ and the maximum of the piston speed ummax, i.e. the ratio value um/ummax. The continuous curve describes the output parameters for the exhaust system temperature interval between $520^{\circ}$ and $620^{\circ} \mathrm{C}$. The dashed curve is valid for the interval between $420^{\circ}$ and $520^{\circ} \mathrm{C}$.

A significant difference among the output parameters is visible after comparison of both curves. The optimal output values are reached in the temperature interval between $520^{\circ}$ and $620^{\circ} \mathrm{C}$. The engine torque is reduced significantly to the level $75 \%$ of the um/um max if the temperature is below $520^{\circ} \mathrm{C}$. The output characteristic is improved up to the level $90 \%$ of the um/ummax. Another problem is in the point 95\%, where the torque is dropped steeply. This phenomenon causes braking of the engine and it can be critical for the racing engines because the sudden decrease of the torque arises in the framework of the operational speed range. The Fig. 7 compares the output parameters for the temperature interval of the exhaust pipe between $520^{\circ}$ to $620^{\circ} \mathrm{C}$ with the output parameters for higher temperatures, namely from $620^{\circ}$ up to $720^{\circ} \mathrm{C}$. The differences among the output parameters are also important as well as in the case of overcooled exhaust system (Fig. 6). If the exhaust pipe is overheated so the engine torque is rising up to the level $68 \%$ of the um/ummax what is analogous to the optimal temperature interval. The characteristic is improved from the $68 \%$ up to the $75 \%$ and after this point it is declining steeply to the local minimum value. After this declining the curve is rising again up to the peak $92 \%$, which is identical with the compared temperature interval between $520^{\circ}$ and $620^{\circ} \mathrm{C}$. According to the analysis of the obtained results it is possible to say that for this engine the optimal interval of operational temperatures in the exhaust pipe is from $520^{\circ}$ to $620^{\circ} \mathrm{C}$. However, in the limit points of this temperature interval, i.e. in the points $520^{\circ} \mathrm{C}$ and $620^{\circ} \mathrm{C}$ the output characteristics are not optimal. The best behaviour of the torque is reached in the middle value of the temperature interval, i.e. in the point $570^{\circ} \mathrm{C}$. Between $420^{\circ}$ and $520^{\circ} \mathrm{C}$ is the exhaust system overcooled. The 
engine characteristics are improved significantly for the higher temperatures and the exhaust pipe is shortened theoretically. The output characteristic is relatively suitable between $620^{\circ}$ and $720^{\circ} \mathrm{C}$ despite the fact of reduced torque at the $68 \%$ of um/ummax. This statement is true especially for the temperature $620^{\circ} \mathrm{C}$. If the temperature is increasing further, the system is overheated and the exhaust pipe is theoretically shortened enormously. The optimal value of the exhaust system temperature was applied in all the next experimental measurements (Fig. $8 \div 14$ ) and the curve obtained between the temperatures from $520^{\circ}$ to $620^{\circ} \mathrm{C}$ (Fig. 6, 7) served as a base for the next comparisons.

The Fig. 8 illustrates the comparison of output parameters for the complete system of the inlet and exhaust pipe but in the second case the exhaust pipe is shortened about $10 \mathrm{~mm}$ in the primary pipe area. The continuous curve represents a comparative output of the complete system at optimal operational interval. The dashed characteristic means an output of the shortened exhaust pipe according to the scheme in the bottom part of this Fig. 8. It is evident from the comparison of these characteristics that the output curve was shifted into the area of higher engine speed due to shortening of the exhaust pipe. The maximal peak was shifted to the right about approx. $4 \%$ of the um/ummax.

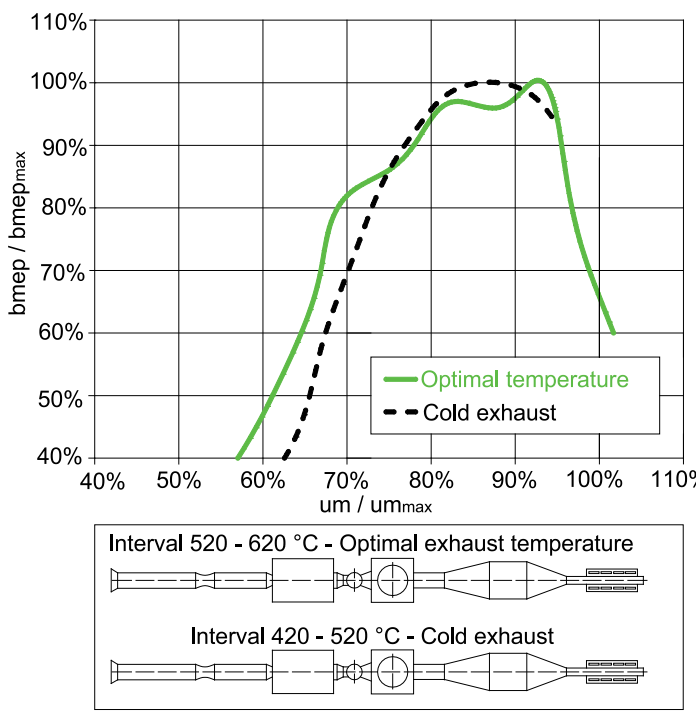

Fig. 6: Dimensionless bmep for various temperature states of the exhaust system.
The fourth graph concerning the exhaust system is in the Fig. 9. It is focused to influence of the silencer on the output characteristic. The output characteristic of the complete system without the silencer is dashed. Both comparative curves are almost identical. Removing of the silencer caused a drop of the engine torque at value interval from $60 \%$ to $66 \%$ of the $u m /$ ummax. $_{\text {max }}$

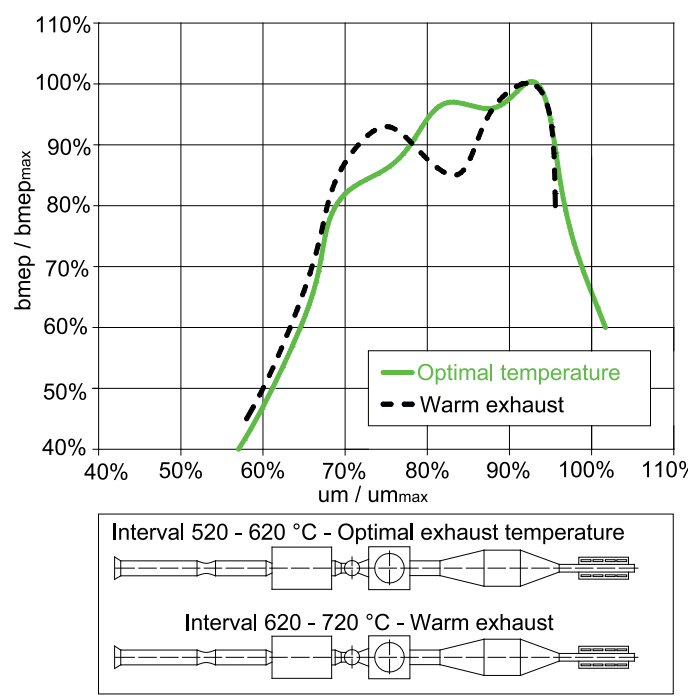

Fig. 7: Dimensionless bmep for various temperature states of the exhaust system.

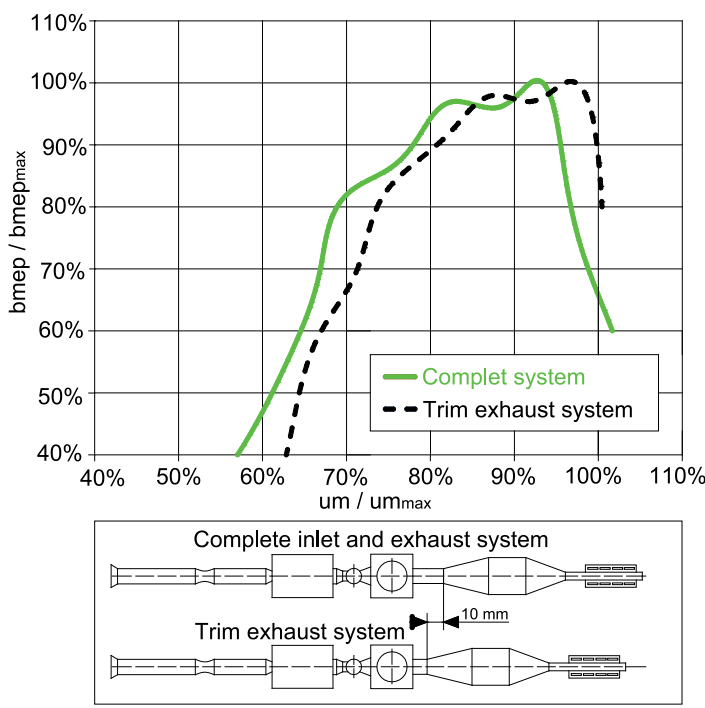

Fig. 8: Dimensionless bmep for various lengths of the exhaust system. 


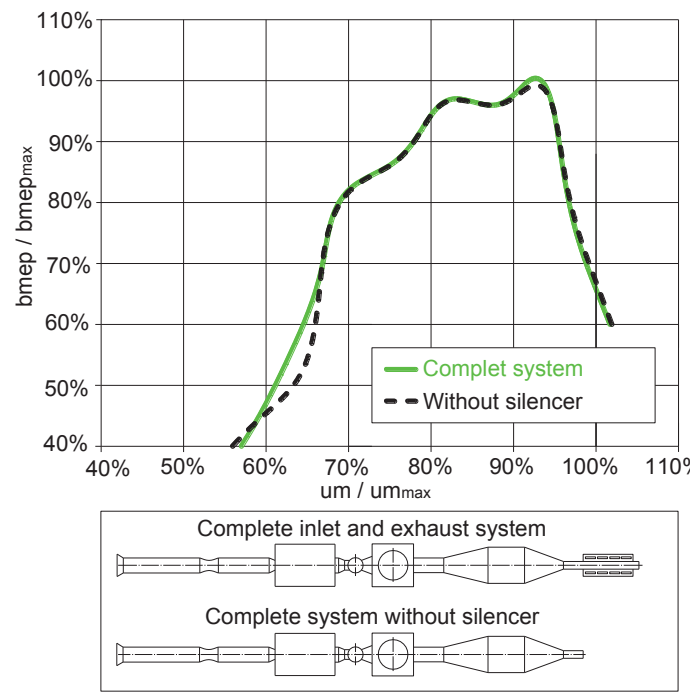

Fig. 9: Dimensionless bmep for the various arrangements of the exhaust system.

\section{Influence of the Inlet System}

Application of the turbocharging for motorbike engines is problematic and therefore it is used the thrust loading system. This system has also disadvantages and consequently was developed and patented the system of thrust-ejector suction (Fig. 2). This system was applied for the racing motorbike (Fig. 1). The main idea of this new solution is to use for the suction process the phenomenon of the exhaust gases oscillation, which is typical for the exhaust pipe. The principle of the thrust-ejector system is as follows: the suction air is flowing through the inlet hole (1) due to underpressure. The air is streaming in the inlet pipe (2) to the ejector (3) whereas its speed is increased due to the contracted ejector cross-section. The suction air follows through the compression pipe (4) into the airbox (5) and next direct to the carburettor, (Fig.1). The experimental measurements performed in this section are oriented to various configurations of inlet pipes.

According to the obtained experimental results it is possible to say that the inlet pipe influence on the final values of the engine torque is less than influence of the exhaust system.

The Fig. 10 compares output characteristic of the complete suction and exhaust system (continuous line) with the basic configuration characteristic (dashed line). It is evident from the comparison of these curves that the engine torque behaviour has got two points of its maximum, namely at the values $68 \%$ and $83 \%$ of the $u m / u m \max$.

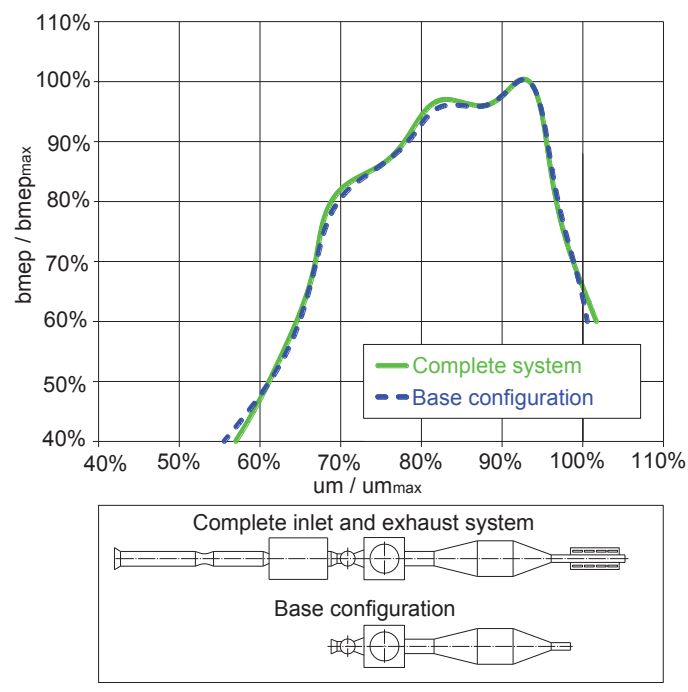

Fig. 10: Dimensionless bmep for the various configurations of the inlet and exhaust system.

The Fig. 11 demonstrates output parameters in the case of the comparison between the complete configuration of the inlet/exhaust piping with the atmospheric air intake and the same system with the pressurized air intake (overpressure value is 80 $\mathrm{kPa}$ - dashed curve). In this case the increment of torque was in the critical area $88 \%$ of the $u m /$ ummax. $_{\text {ma }}$

The Fig. 12 illustrates results of the measurements performed after removing of the secondary part from the inlet pipe but the airbox remained. The dashed output characteristic shows a significant reduction of the torque at the $75 \%$ and the increase to the $82 \%$ of the um/ummax.

The final part of the measuring was focused on investigation of the air filter influence (Fig. 13). The dashed curve was measured with the installed air filter and it is identical with the comparing characteristic at the values over $78 \%$ of the $\mathrm{um} /$ ummax. It can be seen a moderate decrease of this curve (up to this value) in comparison to the reference curve, what is caused due to a suction resistance of the air filter.

The final comparison offers an evaluation between the patented inlet system and the basic configuration (Fig. 14). The continuous curve 

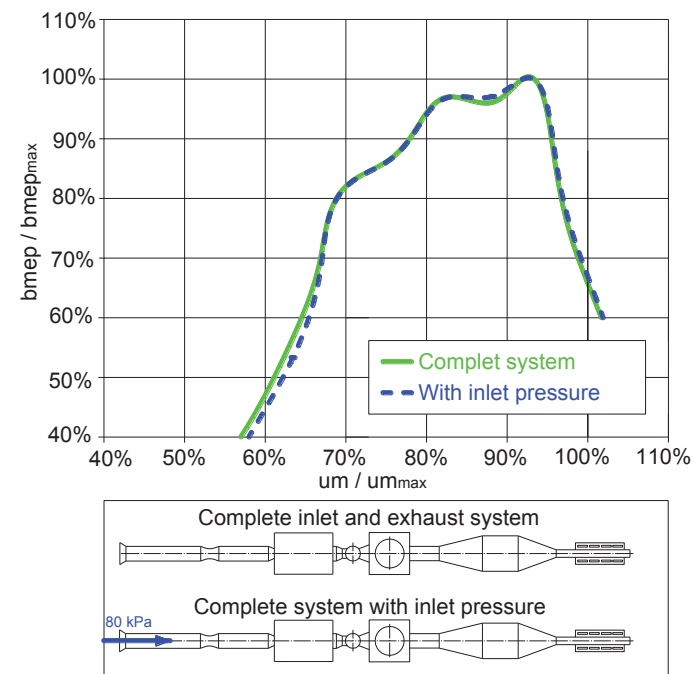

Fig. 11: Dimensionless bmep for the atmospheric and pressurized air intake.
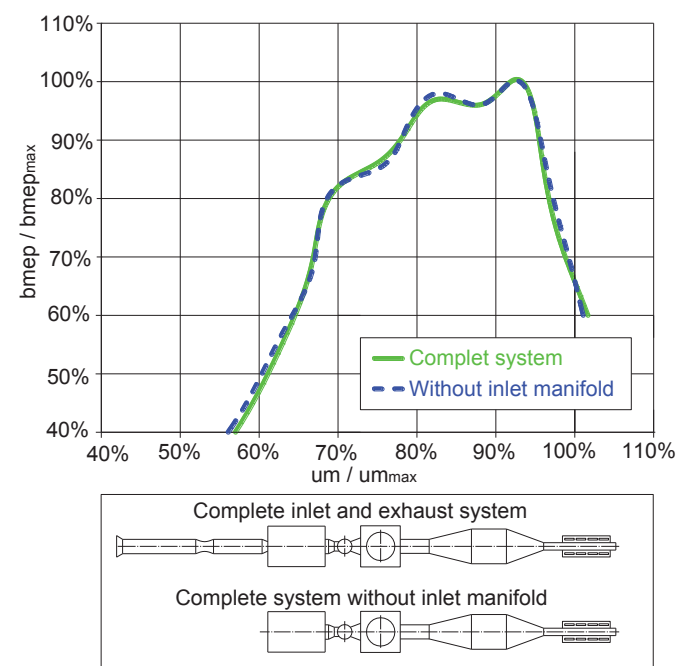

Fig. 12: Dimensionless bmep for the various configurations of the inlet system.

illustrates the basic configuration, which has got the best increase of the power output value up to the $65 \%$ of the um/ummax. From this point is evident a positive impact of the supercharging, i.e. a distinctive growth of the engine torque, excepting the point 75\%, where the both curves are in a single-point contact. The both outputs are common as far as in maximal values at the $92 \%$ of the $u m / u_{\text {max }}$.

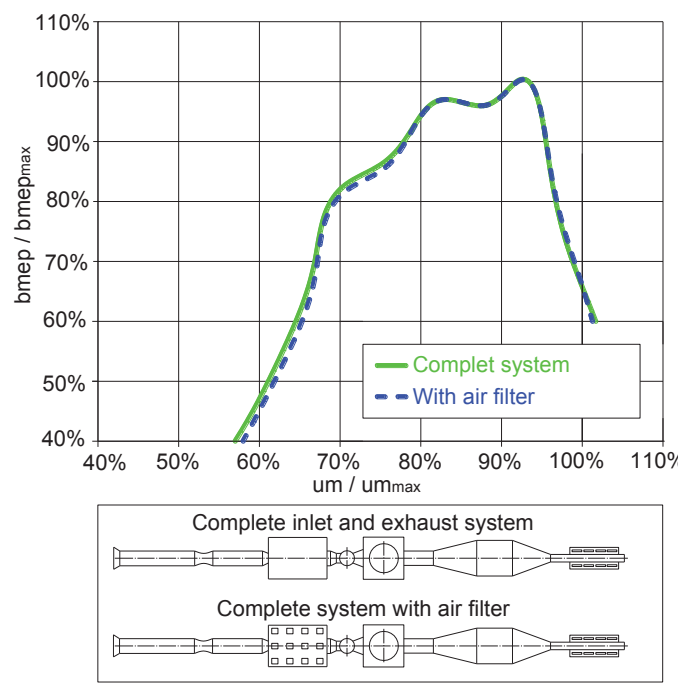

Fig. 13: Dimensionless bmep for the various configurations of the airbox.

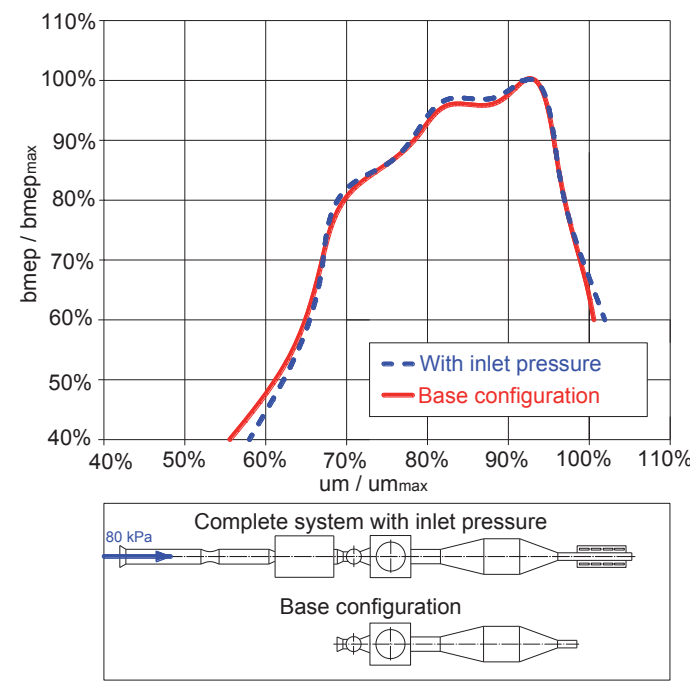

Fig. 14: Dimensionless bmep for the various configurations of the airbox.

\section{Conclusions}

In this article there are presented the analytical relations and experimental measurements obtained and performed during testing of the various configurations of the inlet and exhaust system specified for the racing engine. Several systems were developed and analysed individually each of them. The measurements were focused on: 
1. Analysis of the exhaust system:

$\checkmark$ determination of the optimal operational interval,

$\checkmark$ changing of the exhaust pipeline length,

$\checkmark$ influence of the silencer.

\section{Investigation of the developed and patented inlet air} inlet system:

$\checkmark$ comparison of the complete system with the basic version,

$\checkmark$ influence of the pressurised air intake,

$\checkmark$ influence of the secondary inlet pipe,

$\checkmark$ influence of the air filter.

The low-level temperature in the exhaust pipe means that the mixture is very rich (redundancy of the fuel) and for this reason the mixture is burning imperfectly. The high temperature in the exhaust pipe corresponds to the lean mixture, it is burning down in the exhaust pipe and this process lasts longer (lack of fuel).

The optimal temperature in the exhaust pipe is related to the optimal mixture composition and such mixture is able to transform heat to the mechanical energy with a high efficiency. From this knowledge it is evident that the exhaust pipe temperature is substantial for the power output engine characteristic. It is necessary to ensure an optimal interval of this temperature. The shortening of the exhaust system length in the area of the exhaust tube enables to shift the engine torque towards a higher operational engine speed. This fact enables variability of the power output curve according to the concrete requirement of the given transport vehicle. The influence of the silencer is evident predominately in the area of a low-level engine speed.

The system thrust-ejector air inlet is specified for all single-track vehicles equipped with the piston combustion engine. This system is designed in such way, which makes possible to improve a filling of the cylinder with fresh fuel mixture (fuel with air), i.e. it has got a direct impact to a growth of the engine power output. Application of this newly developed system improves a technical level and a reliability of these engines. The best results were recorded at high speeds. The Fig. 14 presents the global benefit of this technical solution in comparison to the basic version. An importance of the inlet system for the racing engine tuning and improving is very considerable despite of the fact that a benefit in the area of the inlet system is not as essential as in the area of the exhaust system.

\section{Acknowledgments}

At the present time the problem is solved in the framework project "VEGA 1/0197/14 Research of the new methods and innovative design solutions to increase efficiency and to reduce emissions of a vehicle drive unit with an assessment of the potential operational risks".

\section{References}

[1] BENSON, RS.: The thermodynamics and gas dynamics of internal combustion engines. In: Horlock J.H, Winterbone D.E, editors, vol. 1. Oxford: Clarendon Press; 1982.

[2] WINTERBONE, D.E.; Pearson, R.J.: Design techniques for engine manifolds: wave action methods for IC engines. London: Professional Engineering Publishing Ltd.; 1999.

[3] WINTERBONE, D.E.; PEARSON, R.J.: Theory of engine manifolds design: wave action methods for IC engines. London: Professional Engineering Publishing Ltd.; 2000.

[4] SELAMETA, A.; KOTHAMASUA, V.; NOVAKB, J.M.; KACH, R.A.: Experimental investigation of in-duct insertion loss of catalysts in internal combustion engines. Appl. Acoust. 2000; 60:451-87.

[5] PAYRI, F.; TORREGROSA. A.J.; PAYRI, R.: Evaluation through pressure and mass velocity distributions of the linear acoustical description of I.C. engine exhaust systems. Appl. Acoust. 2000; 60:489-504.

[6] HARRISON, M.F.; DE SOTO, I.; RUBIO UNZUETA, P.L.: linear acoustic model for multicylinder IC engine inlet manifolds including the effects of the inlet throttle. J. Sound. Vib. 2004; 278:975-1011.

[7] DAVIES, P.; Holland, K.: Engine inlet and exhaust noise assessment. J. Sound Vib. 1999; 223(3):425-44.

[8] BIGOŠ, P., - PUŠKÁR, M.: Increasing of power output of racing motorcycle engine using of exhaust system optimisation / Peter Bigoš, Michal Puškár - 2011. In: Acta Mechanica Slovaca. Roč. 15, č. 1 (2011), s. 70-77. - ISSN 1335-2393

[9] ALTEN, H.; ILLIEN, M.: Demands on formula one engines and subsequent development strategies. SAE paper 2002-013359; 2002.

[10] OHATA, A.; ISHIDA, Y.: Dynamic inlet pressure and volumetric efficiency of four cycle four cylinder engine, SAE paper 820407; 1982

[11] PIGNONE, G.A.; VERCELLI, R.U.: Motori ad Alta Potenza Specifica, Giorgio Nada, editor. 2nd ed.; 2003.

[12] PUŠKÁR, M.; BIGOŠ, P.: Method for accurate measurements of detonations in motorbike high speed racing engine, Measurement 2012, Vol. 45, no. 3 (2012), p. 529-534, ISSN 0263-2241

[13] PUŠKÁR, M.; BIGOŠ, P.; PUŠKÁROVÁ, P.: Accurate measure- 
Acta Mechanica Slovaca

Journal published by Faculty of Mechanical Engineering - Technical University of Košice

ments of output characteristics and detonations of motorbike high-speed racing engine and their optimization at actual atmospheric conditions and combusted mixture composition, Measurement 2012, Vol. 45, no. 5 (2012), p. 1067-1076, ISSN 0263-2241

[14] PUŠKÁR, M.; BIGOŠ, P.; BALÁŽIKOVÁ, M.; PEY̌KOVÁ, V.: The measurement method solving the problems of engine output characteristics caused by change in atmospheric conditions on the principle of the theory of optimal temperature range of exhaust system, Measurement 2013, Vol. 46, no. 1 (2013), p. 467-475, ISSN 0263-2241 